\title{
Antitumor Effects of Proteasome Inhibition in Anaplastic Thyroid Carcinoma
}

\author{
Annette Altmann ${ }^{1,2}$, Annette Markert ${ }^{1,2}$, Vasileios Askoxylakis ${ }^{3}$, Tilman Schöning ${ }^{4}$, Ralf Jesenofsky ${ }^{5}$, \\ Michael Eisenhut ${ }^{6}$, and Uwe Haberkorn ${ }^{1,2}$ \\ ${ }^{I}$ Department of Nuclear Medicine, University Hospital Heidelberg, Heidelberg, Germany; ${ }^{2}$ Clinical Cooperation Unit Nuclear \\ Medicine, German Cancer Research Center (DKFZ) and University Hospital Heidelberg, Heidelberg, Germany; ${ }^{3}$ Department \\ of Radiooncology, University Hospital Heidelberg, Heidelberg, Germany; ${ }^{4}$ Department of Pharmacy, University Hospital Heidelberg, \\ Heidelberg, Germany; ${ }^{5}$ Department of Medicine II, Medical Faculty of Mannheim, Mannheim, Germany; and ${ }^{6}$ Department \\ of Radiopharmaceutical Chemistry, German Cancer Research Center (DKFZ), Heidelberg, Germany
}

The ubiquitin-proteasome pathway has been identified as a potential molecular target for cancer therapy. In this study, we investigated the effect of the proteasome inhibitor bortezomib on anaplastic thyroid carcinoma (ATC) characterized by complete refractoriness to multimodal therapeutic approaches. Methods: The ATC cell lines C643 and SW1736 were treated with bortezomib ( $1 \mathrm{nM}$ to $1 \mu \mathrm{M}$ ) for 12-72 $\mathrm{h}$. Thereafter, growth inhibition was analyzed by thymidine uptake experiments and determination of the viable cell number. Apoptosis was measured and a cell cycle analysis was done. Using gene chip analysis and the real-time quantitative PCR system, we measured transcriptional changes. The activity of the nuclear factor (NF)- $\mathrm{B}$ and p53 signal transduction pathways was monitored using the reporter constructs pNF- $\mathrm{B}$-TA-Luc and pp53-TA-Luc in the luciferase activity assay. Uptake measurements using ${ }^{3} \mathrm{H}-$ FDG, ${ }^{14} \mathrm{C}$-aminoisobutyric acid, and $\mathrm{Na}^{125}$ iodide were performed to investigate metabolic changes and iodide symporter activity in vitro. Moreover, the ${ }^{18} \mathrm{~F}-\mathrm{FDG}$ uptake was evaluated in ATC tumor-bearing nude mice 1 or $2 \mathrm{~d}$ after treatment with bortezomib. Results: Bortezomib induced growth inhibition, apoptosis, and $\mathrm{G}_{2}-\mathrm{M}$ cell cycle arrest associated with upregulation of $\mathrm{p} 21^{\mathrm{CIP} 1 / \mathrm{WAF} 1}$ expression in SW1736 and C643 cells. Moreover, the glucose metabolism and aminoisobutyric acid uptake significantly decreased in vitro in both of the ATC cell lines in vivo only in SW1736 tumors at $2 \mathrm{~d}$ after the bortezomib treatment. The transcriptional profile in bortezomib-treated SW1736 and C643 cells revealed increased expression of genes involved in stress response, apoptosis, regulation of the cell cycle, and differentiation. Using real-time quantitative PCR for the quantification of gene expression, we additionally noticed upregulation of the tumor necrosis factor-related apoptosis-inducing ligand and the thyroid-specific transcription factors Pax8 and TTF-1, leading to expression of the thyroid-specific target genes thyroglobulin, sodium iodide symporter, thyroperoxidase, and thyroid-stimulating hormone receptor and to a moderate accumulation of iodide in ATC cells. Conclusion: On the basis of our data, bortezomib represents a promising antineoplastic agent

Received Nov. 25, 2011; revision accepted May 31, 2012.

For correspondence or reprints contact: Annette Altmann, Department of Nuclear Medicine, University Hospital Heidelberg, Im Neuenheimer Feld 400, 69120 Heidelberg, Germany.

E-mail: a.altmann@dkfz.de

Published online Oct. 10, 2012.

COPYRIGHT (C) 2012 by the Society of Nuclear Medicine and Molecular Imaging, Inc. for the treatment of ATC. To improve the clinical outcome, further investigation into the potential of bortezomib therapy of thyroid cancer is clearly warranted.

Key Words: anaplastic thyroid carcinoma; proteasome inhibition; transcriptional profile; redifferentiation; iodide transport

J Nucl Med 2012; 53:1764-1771

DOI: 10.2967/jnumed.111.101295

$\mathbf{T}$ hyroid carcinomas mostly appear as well-differentiated papillary and follicular tumors that are successfully treated by thyroidectomy, radioiodide therapy, and thyroid-stimulating hormone (TSH)-suppressive L-thyroxine medication. Occasionally, however, some patients develop more aggressive disease with local recurrence and distant metastasis due to dedifferentiation of the tumor, which is associated with a decrease or even loss of thyroid-specific gene expression and the inability to take up radioiodide (1). The prognosis is even worse for anaplastic thyroid carcinoma (ATC), which completely lacks thyroid-specific gene expression (2) and is not accessible to any therapeutic regimes (3). Because the overall median survival of patients with ATC is limited, there is a need for new therapeutic strategies for the treatment of these tumors.

As a major component for the degradation of proteins involved in cell survival, proliferation, and regulation of apoptosis and transcription, the ubiquitin-proteasome pathway has been identified as a potential molecular target for cancer therapy (4). Proteasome inhibitors have been shown to interfere with key steps of tumor cell regulation, leading to the inhibition of proliferation and death of neoplastic cells both in vitro and in vivo (5). Accordingly, the proteasome inhibitor bortezomib (PS-341, Velcade; Janssen-Cilag) provides strong antiproliferative effects in a variety of hematologic and solid cancer cells $(6,7)$ and has marked clinical activity even in the setting of relapsed refractory multiple myeloma (8).

In the attempt to use proteasome inhibition for the treatment of undifferentiated thyroid tumors, we investi- 
gated the cellular response of the ATC cell lines SW1736 and C643 after exposure to bortezomib and applied combined gene expression profiling and real-time quantitative PCR (qPCR) to characterize the corresponding molecular pathways. Here, we show that in these cells bortezomib induced apoptosis, cell cycle arrest, changes in metabolism, and upregulation of genes involved in thyroid-specific functional activity.

\section{MATERIALS AND METHODS}

\section{Cell Cultures and Treatment}

The ATC cell lines SW1736 and C643 were cultured in RPMI 1640 medium (Gibco) supplemented with $10 \%$ fetal calf serum at $37^{\circ} \mathrm{C}$ in an atmosphere of $95 \%$ air and $5 \% \mathrm{CO}_{2}$. For the experiments, SW1736 and C643 cells were seeded in 6-well plates (cell cycle analysis, cell uptake measurements), in 12-well plates (apoptosis measurement), or in tissue culture flasks (RNA extraction) and cultured until $70 \%$ confluence was reached. Thereafter, the cells were treated with 10 -fold dilutions $(10 \mathrm{nM}, 100 \mathrm{nM}$, and $1 \mu \mathrm{M})$ of bortezomib for $12,24,48$, and $72 \mathrm{~h}$, respectively, before experimental procedures were performed. The viable cell number was determined in a Vi-CELL XR Cell Viability Analyzer (Beckmann Coulter).

\section{Total RNA Extraction}

The cells were lysed in Trizol (Invitrogen), and the RNA was purified by chloroform extraction and centrifugation, followed by isopropanol precipitation for $10 \mathrm{~min}$ at room temperature. The quality and the concentration of the RNA dissolved in diethylpyrocarbonate$\mathrm{H}_{2} \mathrm{O}$ was photometrically determined by the 280 -to- 260 ratio in the Nano Drop ND 100 (Peqlab).

\section{Real-Time qPCR}

After digestion of the RNA with RQ1 RNase-Free DNase I (Promega), reverse transcription of $2 \mu \mathrm{g}$ of RNA was performed using the high-capacity RNA-to-complementary DNA kit (Life Technologies) as described by the manufacturer. The real-time qPCR of samples $(n=2)$ was performed on the Step One Plus qPCR system (Life Technologies) using the TaqMan Fast Univ PCR Master Mix and the TaqMan gene expression assays (Life Technologies) Hs01121172_m1 (p21 ${ }^{\mathrm{CIP} / \mathrm{WAF} 1)}$, Hs00153349_m1 (p53), Hs00247591_m1 (Pax8), Hs00201121_m1 (TTF-1), Hs00794359_m1 (thyroglobulin), Hs01053846_m1 (thyroidstimulating hormone receptor [TSHr]), Hs00892519_m1 (thyroperoxidase), Hs00166567_m1 (iodide symporter [NIS]), Hs00234355_m1 (tumor necrosis factor[TNF]-related apoptosis-inducing ligand [TRAIL]), and Hs01043166_m1 (TRAIL receptor DR5/TRAIL-R2) as specific probes and glyceraldehyde 3-phosphate dehydrogenase (GAPDH) (Hs99999905_m1) as an endogenous control. The relative quantification of transcription was determined using the formula $2^{-\Delta \Delta \mathrm{Ct}}$ (9).

\section{Measurement of Apoptosis}

Apoptosis was measured by the Caspase-Glo 3/7 assay (Promega) as recommended by the manufacturer. For modulation, the cells were lysed with Luciferase Cell Culture Lysis Reagent (200 $\mu \mathrm{L} /$ well; Promega). Thereafter, the lysate was centrifuged at $12,000 \mathrm{~g}$ for $15 \mathrm{~s}$, and $50 \mu \mathrm{L}$ of supernatant were incubated with $50 \mu \mathrm{L}$ of Caspase-Glo Reagent (Promega) for $1 \mathrm{~h}$ at room temperature before the caspase activity was quantified in the luminometer.

\section{Cell Cycle Analysis}

SW1736 and C643 cells were washed twice with phosphatebuffered saline (PBS), trypsinized, and centrifuged in culture medium. The cell pellet was resuspended in PBS and diluted 10-fold in 70\% ethanol overnight. After being washed and centrifuged in PBS, the pellet was resuspended in $0.5 \mathrm{~mL}$ of $2.1 \%$ citric acid $/ 0.5 \%$ polysorbate 20 , and $3 \mathrm{~mL}$ of $7.1 \% \mathrm{Na}_{2} \mathrm{HPO}_{4} / 0.5 \% 4^{\prime}$,6-diamidino-2phenylindole solution (10 mg of 4',6-diamidino-2-phenylindole in $28.57 \mathrm{~mL}$ of $\mathrm{H}_{2} \mathrm{O}$ ) was added for fluorescence-activated cell sorting analysis.

\section{Thymidine Incorporation into DNA}

The cells were pulsed for $2 \mathrm{~h}$ with $74 \mathrm{kBq}$ of methyl- ${ }^{3} \mathrm{H}-$ thymidine (American Radiolabeled Chemicals; specific activity, $370 \mathrm{GBq}[10 \mathrm{Ci}] / \mathrm{mmol}$ ) per milliliter of medium and $0.05 \mathrm{mM}$ cold thymidine. After the cells had been washed 3 times with ice-cold PBS, lysis was initially performed with $0.5 \mathrm{~mL}$ of $0.5 \mathrm{M}$ perchloric acid using a cell scraper. After $30 \mathrm{~min}$ on ice, the lysate was stirred in a vortex mixer and centrifuged at $1,500 \mathrm{~g}$ for $5 \mathrm{~min}$ at $0^{\circ} \mathrm{C}$. The supernatant (acid-soluble fraction) was removed, and the pellet (acid-insoluble fraction) was lysed in $0.5 \mu \mathrm{L}$ of $0.3 \mathrm{~N} \mathrm{NaOH}$. The radioactivity in $300-\mu \mathrm{L}$ aliquots of the acid-insoluble fraction was quantified by scintillation counting.

\section{${ }^{3}$ H-FDG Uptake}

The uptake experiments were performed in glucose-free RPMI 1640 medium. After preincubation for $30 \mathrm{~min}, 37 \mathrm{kBq}$ of 2-fluoro2-deoxy-D-glucose, $\left[5,6-{ }^{3} \mathrm{H}\right]$ (ART 0105 [37 MBq $\left.(1 \mathrm{mCi}) / \mathrm{mL}\right]$; specific radioactivity, $740 \mathrm{GBq}$ [20 Ci/mmol]; radioactive concentration, 36,963 kBq [999 $\mu \mathrm{Ci}] / \mathrm{vial})$, per milliliter of medium and cold FDG (final concentration, $0.1 \mathrm{mM}$ ) were added. After incubation for $10 \mathrm{~min}$, the cells were washed twice with ice-cold PBS. The lysis was done in $0.5 \mu \mathrm{L} 0.3 \mathrm{~N} \mathrm{NaOH}$. The radioactivity in $300-\mu \mathrm{L}$ aliquots was quantified by scintillation counting.

\section{lodide Uptake and Efflux}

The iodide uptake was determined as described previously (10). Briefly, ATC cells were incubated with $74 \mathrm{kBq}$ of $\mathrm{Na}^{125} \mathrm{I}$ (Amersham Buchler; specific activity, $625.3 \mathrm{MBq} / \mu \mathrm{g}$; radioactive concentration, 3.7 $\mathrm{GBq} / \mathrm{mL}$; radiochemical purity, 99.3\%) per well for $1 \mathrm{~h}$. The cells were washed twice with ice-cold PBS and lysed with $0.3 \mathrm{~N}$ $\mathrm{NaOH}$ on ice. Thereafter, the radioactivity in the lysates was measured using a Cobra II $\gamma$-Counter (Packard). For modulation, the cells were incubated with or without $\mathrm{TSH}(50 \mu \mathrm{U} / \mathrm{mL})$ for $4 \mathrm{~h}$ before $\mathrm{Na}^{125} \mathrm{I}$ was added. To determine the iodide efflux, the $\mathrm{Na}^{125}$ I-containing medium was exchanged after $1 \mathrm{~h}$ by nonradioactive medium, and the cells were incubated again for $20 \mathrm{~min}$ and prepared for the measurement of radioactivity as described.

\section{Animal Studies}

Female BALB/c (nu/nu) mice (age, $6 \mathrm{wk})$ were supplied by Charles River Laboratories. All animal studies were performed in compliance with the national laws relating to the conduct of animal experimentation. After inoculation of cell suspensions $(4 \times$ $10^{6}$ cells per animal) into the thigh of the mice, tumor growth was measured using calipers. ${ }^{18}$ F-FDG PET was performed when the tumors reached diameters of 7-13 mm (8-10 wk after transplantation). The animals (weight, 18-23 g) were studied before and at $2 \mathrm{~d}$ after treatment with bortezomib $\left(2.25 \mathrm{mg} / \mathrm{m}^{2}\right)$, with no statistically significant difference in size of tumors before and after treatment. Before PET, the animals were kept fasting for $4 \mathrm{~h}$. The animals were kept in an inhalation narcosis with sevorane 
FIGURE 1. Proliferation of SW1736 (A) and C643 (B) cells was evaluated by ${ }^{3} \mathrm{H}$-thymidine incorporation in presence of $0.05 \mathrm{mM}$ cold thymidine into acid-insoluble cell fraction after exposure to bortezomib $(10 \mathrm{nM}$, $100 \mathrm{nM}$, and $1 \mu \mathrm{M})$ graded for 12,24 , and $48 \mathrm{~h}$. Specific activity (pmol) of each sample was calculated and normalized to $10^{5}$ cells. Data represent mean values and SD of triplicate samples.
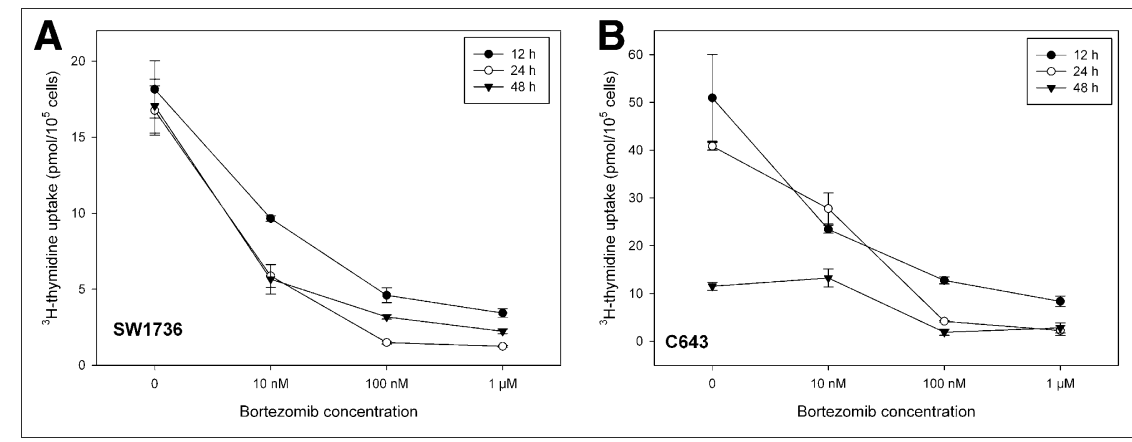

(0.5 volume- $\%$ ) and oxygen (flow, $500 \mathrm{~mL} / \mathrm{min}$ ) during the PET examination. The plasma glucose level of the animals was determined using a blood glucose sensor electrode (MediSense), revealing values between 78 and $145 \mathrm{mg} / \mathrm{dL}$. A transmission scan was obtained for $10 \mathrm{~min}$ before tracer administration with 2 rotating germanium pin sources to obtain cross sections for attenuation correction. After the acquisition of transmission data for attenuation correction, $6 \mathrm{MBq}$ of ${ }^{18} \mathrm{~F}-\mathrm{FDG}$ in $0.3 \mathrm{~mL}$ were administered into the tail vein, and PET data were acquired for $1 \mathrm{~h}$ in list mode on a Siemens Inveon scanner using a matrix of $256 \times 256$ (pixel size, $0.3882 \times 0.3882 \times 0.796 \mathrm{~mm})$. Thereafter, images were reconstructed at definite times after tracer administration $(2 \times 15,8 \times$ $30,5 \times 60,4 \times 120,2 \times 210$, and $7 \times 300 \mathrm{~s}$ ). The images were reconstructed iteratively using the space-alternating generalized expectation maximization method (16 subsets, 4 iterations), applying a median root before correction, and were converted to standardized uptake value (SUV) images on the basis of the formula $\mathrm{SUV}=$ tissue concentration $(\mathrm{Bq} / \mathrm{g}) /($ injected dose $[\mathrm{Bq}] /$ body weight $[\mathrm{g}])$. The individual tumor SUV was calculated for each study as the mean of the last 2 time frames from 50 to $60 \mathrm{~min}$ after injection.

\section{Statistical Analysis}

Data were analyzed using the paired 2-tailed Student $t$ test, and significance was assumed at a $P$ value of less than 0.05 .

\section{RESULTS}

\section{Effect of Bortezomib on Proliferation and Cell Cycle}

After incubation with increasing concentrations of bortezomib for 12, 24, and $48 \mathrm{~h}$, a time- and dose-dependent growth inhibition of SW1736 and C643 cells was measured by ${ }^{3} \mathrm{H}$-thymidine uptake (Fig.1) and determination of the cell number (Supplemental Fig. 1; supplemental materials are available online only at http://jnm.snmjournals.org). In SW1736 cells (Fig. 1A) treated with $1 \mu \mathrm{M}$ bortezomib, a decrease of the ${ }^{3} \mathrm{H}$-thymidine uptake between $81 \%$ and $96 \%$ was measured. The same concentration reduced the proliferation of C643 cells between $76 \%$ and $95 \%$ (Fig. 1B). In addition, the fraction of viable cells was reduced to $25 \%$ and $6.5 \%$ for SW 1736 (Supplemental Fig. 1A) and C643 (Supplemental Fig. 1B), respectively. The growth inhibitory effect of bortezomib was associated with cell cycle arrest (Table 1) and upregulation of the cyclin-dependent kinase inhibitor $\mathrm{p} 21^{\mathrm{CIP} 1 / \mathrm{WAF} 1}$ (Fig. 2). In cells treated with $100 \mathrm{nM}$ bortezomib, an up to 2-fold accumulation in the $G_{2}-M$ phase and a decrease of both the $G_{1}$ phase cell fraction by $21 \%$ (SW1736) and 45\% (C643) and the S phase cell fraction by 25\% (SW1736) and 17\% (C643) was observed (Table 1). Simultaneously, a more than 11fold and 5.5-fold increased p21 CIP1/WAF1 transcription was measured in SW1736 and C643 cells (Fig. 2), respectively. Previous studies have shown that in thyroid carcinoma cells, bortezomib inhibits the activity of nuclear factor (NF)- $\mathrm{B}$ (11), which has been implicated in tumor development (12). Instead, we measured an up to 9.6-fold $(P \leq 0.05)$ and up to 3.7 -fold $(P \leq 0.05)$ increase of NF- $\mathrm{BB}$ activity in SW1736 (Supplemental Fig. 2A) and C643 cells (Supplemental Fig. 2B), respectively, after the treatment with $100 \mathrm{nM}$ bortezomib. In contrast, neither p53 transcription (Fig. 2) nor p53 activity (Supplemental Fig. 2) was measured using qPCR and the reporter gene assay.

\section{Induction of Apoptosis}

Although induction of $\mathrm{p} 21^{\mathrm{CIP} 1 / \mathrm{WAF} 1}$ expression and $\mathrm{G}_{2}-\mathrm{M}$ phase arrest are implicated in resistance to apoptosis (13), we detected a concentration-dependent increase of the apoptotic cell fraction in both cell lines using the annexin V/ propidium iodide assay (Supplemental Fig. 3) and the measurement of the caspase-3 and caspase-7 activity (Fig. 3). In SW1736 cells, an up to 27-fold increase of caspase- 3 and caspase-7 activity was measured $24 \mathrm{~h}$ after the treatment with bortezomib (Fig. 3A) $(P \leq 0.01)$. In C643 cells, an up to 15 -fold increase of the caspase- 3 and caspase-7 activity was observed at $48 \mathrm{~h}$ after exposure to the proteasome inhibitor (Fig. 3B) $(P \leq 0.01)$. We also found a significant increase of annexin V-labeled SW1736 cells at 24 and $48 \mathrm{~h}$, whereas annexin V-labeled C643 cells were detected only at $48 \mathrm{~h}$ after exposure to bortezomib (Supplemental Fig. 3). Simultaneously, a 19- and 10-fold increased expression of TRAIL and a 2.1- and 2.6-fold increased expression of the TRAIL receptor DR5/TRAIL R-2 were measured by qPCR in SW1736 and in C643 cells (Fig. 3C) exposed to $100 \mathrm{nM}$ bortezomib for $24 \mathrm{~h}$. The expression pattern obtained by the gene chip analysis, however, differed between the ATC cell lines. C643 cells provided increased expression of the growth-arrest and DNA damage-inducible $\alpha$-transcripts and the growth-arrest and DNA damage-inducible (GADD)34 (Supplemental Table 1), which is induced in certain cell lines and correlates with p53-independent apoptosis after 
TABLE 1

Bortezomib Induces $\mathrm{G}_{2}-\mathrm{M}$ Phase Arrest in ATC Cell Lines

\begin{tabular}{|c|c|c|c|c|}
\hline \multirow[b]{2}{*}{ Cell line } & \multirow[b]{2}{*}{ Concentration (nM) } & \multicolumn{3}{|c|}{ Phase } \\
\hline & & $\mathrm{G}_{1}$ & $S$ & $\mathrm{G}_{2}-\mathrm{M}$ \\
\hline \multicolumn{5}{|l|}{ SW1736 } \\
\hline \multirow[t]{2}{*}{$12 \mathrm{~h}$} & 0 & $47.97 \pm 0.78$ & $36.77 \pm 1.07$ & $15.20 \pm 0.29$ \\
\hline & 100 & $38.28 \pm 1.43$ & $32.90 \pm 1.45$ & $28.51 \pm 0.42$ \\
\hline \multirow[t]{2}{*}{$24 \mathrm{~h}$} & 0 & $42.83 \pm 1.5$ & $34.77 \pm 0.35$ & $22.31 \pm 1.02$ \\
\hline & 100 & $34.94 \pm 2.02$ & $38.68 \pm 3.35$ & $26.38 \pm 1.33$ \\
\hline \multirow[t]{2}{*}{$48 \mathrm{~h}$} & 0 & $50.16 \pm 1.42$ & $31.44 \pm 1.4$ & $18.40 \pm 0.02$ \\
\hline & 100 & $48.25 \pm 0.78$ & $23.42 \pm 0.75$ & $28.33 \pm 0.03$ \\
\hline \multicolumn{5}{|l|}{ C643 } \\
\hline \multirow[t]{2}{*}{$12 \mathrm{~h}$} & 0 & $49.57 \pm 0.03$ & $31.25 \pm 0.21$ & $19.17 \pm 0.18$ \\
\hline & 100 & $27.36 \pm 0.13$ & $33.70 \pm 1.29$ & $38.94 \pm 1.42$ \\
\hline \multirow[t]{2}{*}{$24 \mathrm{~h}$} & 0 & $35.90 \pm 1.06$ & $40.71 \pm 0.59$ & $23.39 \pm 1.66$ \\
\hline & 100 & $22.14 \pm 0.03$ & $33.97 \pm 0.34$ & $43.89 \pm 0.37$ \\
\hline \multirow[t]{2}{*}{$48 \mathrm{~h}$} & 0 & $58.27 \pm 1.94$ & $29.32 \pm 0.39$ & $12.41 \pm 1.55$ \\
\hline & 100 & $46.09 \pm 0.72$ & $27.50 \pm 1.33$ & $26.41 \pm 0.35$ \\
\hline
\end{tabular}

Cell cycle analysis of SW1736 and C643 cells incubated without $(0 \mathrm{nM})$ or with bortezomib $(100 \mathrm{nM})$ for indicated times was performed using fluorescence-activated cell sorting analysis. Data represent percentage of cells in $G_{1}, S$, and $G_{2}-M$ phases, indicated as mean values of triplicate samples and SD.

ionizing radiation (14). In contrast, in SW1736 cells, the transcripts of the death-associated protein kinase3, the growth arrest and DNA damage-inducible $\beta$-protein, the TRAIL receptor DR4/TRAIL-R1 and the Fas-associated factor (FAF)1 were upregulated (Supplemental Table 2). When exposed to $10 \mathrm{nM}$ bortezomib, SW1736 cells predominantly provided increased expression of members of the TNF superfamily and the TNF receptor member 6 (Supplemental Table 3).

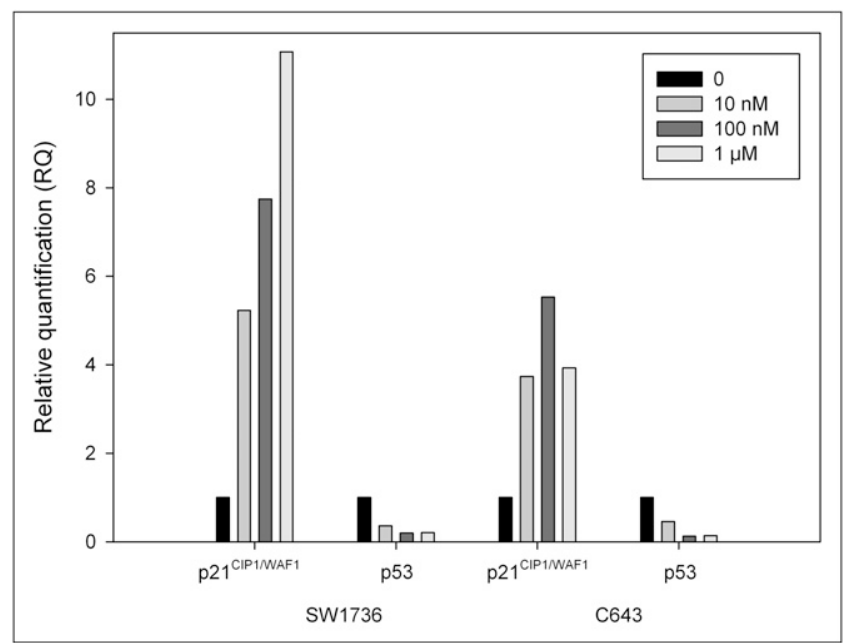

FIGURE 2. Transcription of $\mathrm{p} 21^{\mathrm{CIP} / \mathrm{WAF} 1}$ and $\mathrm{p} 53$ in SW1736 and C643 cells exposed to graded bortezomib concentrations for $24 \mathrm{~h}$ was determined by qPCR using p21 CIP/WAF1 - or p53-specific probe and GAPDH-specific probe as endogenous control. Values represent relative quantification of bortezomib-treated vs. untreated cells.

\section{Determination of Metabolic Changes}

Uptake studies performed to evaluate the effect of bortezomib on the metabolism of the ATC cells revealed a dose- and time-dependent decrease in tracer uptake (Fig. 4). The ${ }^{3} \mathrm{H}-\mathrm{FDG}$ accumulation declined to $1.5 \%$ in SW1736 (Fig. 4A) and to $3.4 \%$ in C643 (Fig. 4B) cells. Similarly, the ${ }^{3} \mathrm{H}$-aminoisobutyric acid uptake decreased to $1.7 \%$ in SW1736 (Supplemental Fig. 4A) and 2.2\% in C463 (Supplemental Fig. 4B) cells.

After transplantation of SW1736 and C643 tumor cells in nude mice in vivo, studies of ${ }^{18} \mathrm{~F}$-FDG uptake were done using PET before and at 1 and $2 \mathrm{~d}$ after bortezomib therapy (Fig. 5; Supplemental Fig. 5). No significant changes were seen on day 1 for either tumor. However, a significant decrease $(45 \%)$ of tracer uptake $(P<0.05)$ was observed for SW1736 tumors on day 2 after therapy.

\section{Transcriptional Profile of Bortezomib-Treated ATC Cells}

A summary of bortezomib-induced transcriptional changes in SW1736 and C643 cells is presented in Supplemental Tables 1, 2, and 3. Besides the induction of both proapoptotic and antiapoptotic protein transcripts of components of the ubiquitin-proteasome pathway - most notably the ubiquitinconjugating enzyme E2H and ubiquitin-specific proteasestranscripts implicated in growth signaling and survival cascades were upregulated. These include the insulin-like growth factor 1 and 2, serine-threonine protein kinase, serine-threonine kinase $17 \mathrm{~b}$, tyrosine kinase transcripts, protein kinase and proteinase inhibitors in C643 cells (Supplemental Table 1), and the insulin-like growth factor receptors 2 and 1 in SW1736 cells (Supplemental Table 2). In addition, in both cell lines bortezomib induced a significant increase of heat 


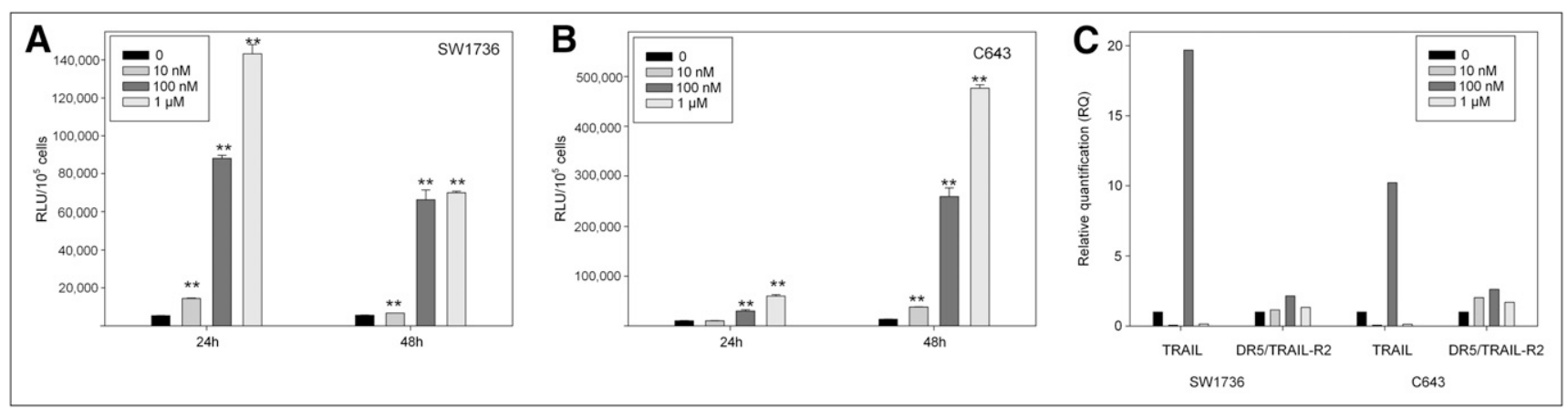

FIGURE 3. Determination of apoptosis in SW1736 (A) and C643 (B) cells treated with increasing bortezomib concentrations for 12, 24, and 48 h. Caspase-3 and caspase-7 activity was measured by Caspase-Glo 3/7 assay (Promega). Data evaluated by luminescence (RLU) and normalization to $10^{5}$ cells represent mean values and SD of triplicate samples. Expression of TRAIL and DR5/TRAIL-R2 in SW1736 and C643 cells $(C)$ exposed to bortezomib for $24 \mathrm{~h}$ was quantified by qPCR using TRAIL- and DR5/TRAIL-R2 probe and GAPDH probe as endogenous control. Values represent relative quantification of bortezomib-treated vs. untreated cells. ${ }^{\star \star} P \leq 0.01$.

shock protein (hsp) transcripts, including the hsp-70, hsp-90, hsp-40, and hsp-27 families. Interestingly, the transcriptional profile of the ATC cells differed with respect to the expression of thyroid-specific transcription factors because in SW1736 cells treated with $10 \mathrm{nM}$ bortezomib, but not in C643 cells, TTF-2 expression was initiated and transcription of Pax 8 and Pax 8 isoforms was increased (Supplemental Table 3).

\section{Induction of Thyroid-Specific Gene Expression}

In ATC expression of thyroid-specific genes and of the transcription factor TTF-1 is completely absent (15). The fact that increased Pax 8 transcription was detected by the gene chip analysis, at least in bortezomib-treated SW1736 cells (Supplemental Table 3), prompted us to use qPCR for the investigation of thyroid-specific gene expression in the ATC cell lines. In fact, after incubation with $100 \mathrm{nM}$ bortezomib for $24 \mathrm{~h}$, a more than 4,500- and 711-fold increase of Pax 8 transcription and a 5- and a 3.4-fold induction of TTF-1 transcription were measured in SW1736 (Fig. 6A) and C643 (Fig. 6B) cells, respectively. In addition, significant changes in thyroid-specific gene expression occurred, leading to a more than 30-fold increase of the thyroglobulin expression and an up to 5- and up to 7.5-fold increase of thyroperoxidase expression and an up to 38- and 10.9-fold upregulation of the TSHr expression in SW1736 (Fig. 6A) and C643 cells (Fig. 6B), respectively. Because Pax8 and TTF-1 interact and synergistically activate transcription of thyroglobulin and thyroperoxidase $(16,17)$, these data provide evidence for their functional activity. The transcription of NIS was most affected by proteasome inhibition, ranging from 23- to 184-fold in SW1736 and 63- to 826-fold in C643 cells; the induction of NIS expression was achieved by the incubation with $100 \mathrm{nM}$ and $1 \mu \mathrm{M}$ bortezomib. Iodide uptake experiments performed to investigate functional activity of NIS revealed a 4.5-fold increase of iodide uptake $(P \leq$ 0.01) in C643 cells exposed to $100 \mathrm{nM}$ bortezomib for $72 \mathrm{~h}$; this increase was followed by an efflux of more than $90 \%$ radioactivity within $20 \mathrm{~min}$ (Fig. $7 \mathrm{~B}, P \leq 0.05$ ). In SW1736 cells (Fig. 7A), a 1.6-fold increase of iodide accumulation was achieved $(P \leq 0.01)$, followed by an efflux of less than $43 \%$ of the intracellular radioactivity $(P \leq 0.01)$, pointing to functional activity of the thyroperoxidase and presence of thyroglobulin. Because NIS activity is affected by TSH (18), and TSHr expression was initiated on bortezomib treatment (Fig. 6), we performed iodide uptake experiments in the presence of TSH. However, in none of the ATC cell lines was an augmentation of iodide accumulation achieved by the addition of TSH (data not shown).

\section{DISCUSSION}

This study demonstrated an antiproliferative effect of bortezomib on the ATC cell lines SW1736 and C643 involving the induction of cell cycle arrest and apoptosis and changes in metabolism and gene expression. Bortezomib induced a dose- and time-dependent growth inhibition, which was

FIGURE 4. Uptake of ${ }^{3} \mathrm{H}-\mathrm{FDG}$ in SW1736 (A) and C643 (B) cells after exposure to different doses of bortezomib for $12-48 \mathrm{~h}$. ATC cell lines were incubated with $37 \mathrm{kBq}$ of ${ }^{3} \mathrm{H}$ FDG and $0.1 \mathrm{mM}$ cold FDG for $10 \mathrm{~min}$, and radioactivity in lysates was quantified by scintillation counting. Specific activity (pmol) of each sample was calculated and normalized to $10^{5}$ cells. Data represent mean values and SD of triplicate samples.
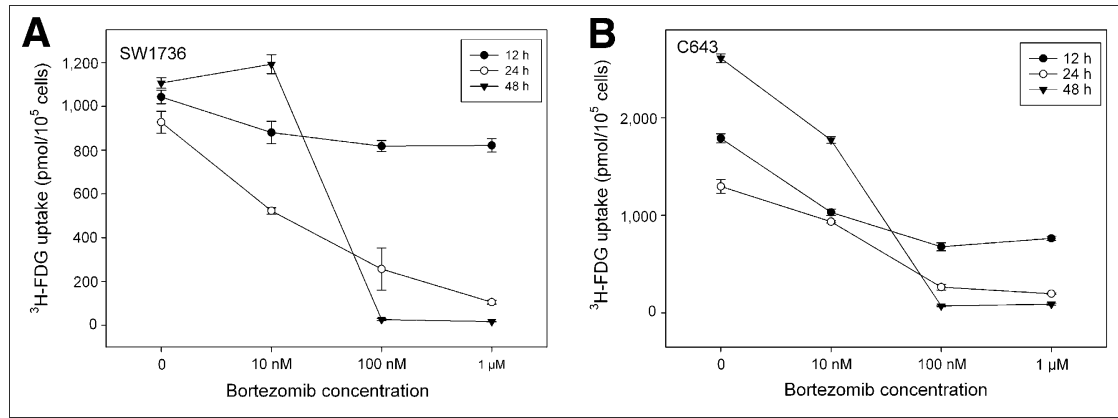


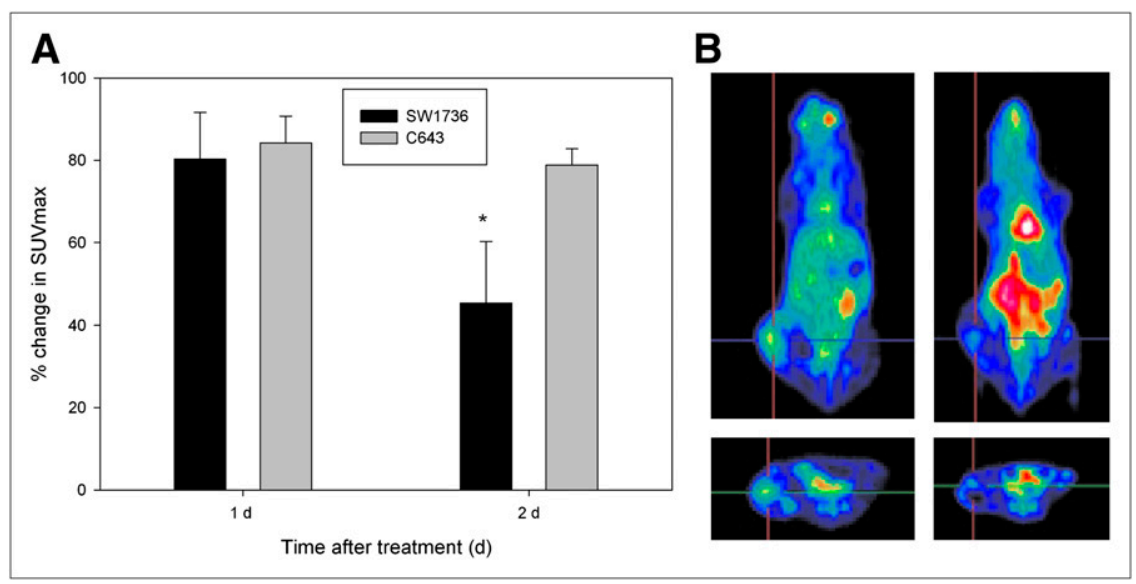

FIGURE 5. (A) Changes (in percentage of pretreatment value in same animal) in ${ }^{18} \mathrm{~F}-$ FDG uptake (maximum SUV) before and 1 and $2 \mathrm{~d}$ after therapy with bortezomib in animals bearing SW1736 and C643 tumors in right thigh (mean and SEM, $n=4$ ). (B) Coronal and transaxial slices of the SW1736 tumor-bearing animal before therapy (left) and $2 \mathrm{~d}$ after therapy (right). ${ }^{\star} P \leq$ 0.05 . associated with an increased $\mathrm{G}_{2}-\mathrm{M}$ phase cell fraction. Given the essential role of $\mathrm{p} 21^{\mathrm{CIP} 1 / \mathrm{WAF} 1}$ in the regulation and maintenance of $\mathrm{G}_{2}-\mathrm{M}$ phase arrest in response to anticancer drugs $(19,20)$, it is not surprising that we measured a significant upregulation of $\mathrm{p} 21^{\mathrm{CIP} 1 / \mathrm{WAF} 1}$ expression in both cell lines.

Although the induction of $\mathrm{p} 21^{\mathrm{CIP} 1 / \mathrm{WAF} 1}$ expression and $\mathrm{G}_{2}-\mathrm{M}$ phase arrest has been demonstrated to impede caspase-3-mediated apoptosis in MCF7 cells (13), we measured an increase of the caspase- 3 and caspase- 7 activity in the ATC cells. In addition, the transcriptional profile revealed an increased expression of the TNF superfamily members including TNF superfamily 10 (TRAIL) and of the TRAIL receptor DR4/TRAIL-R1 in SW1736 cells. Using qPCR for investigation of gene expression, we detected the upregulation of TRAIL expression and, although to a lesser extent, of DR5/TRAIL-R2 expression in both cell lines. Although a caspase-3-independent apoptotic pathway cannot definitively be excluded, we suggest that in ATC cells activation of the caspase- 3 pathway is initiated through the interaction of TRAIL with the specific receptors DR5/TRAIL-R2 or DR4/TRAIL-R1 as already observed for follicular thyroid (21) and renal carcinoma (22).

The determination of metabolic changes after therapeutic intervention has been proven to be valuable for the assessment of early therapy effects (23). Using ${ }^{3} \mathrm{H}$-aminoisobutyric acid and ${ }^{3} \mathrm{H}-\mathrm{FDG}$ as tracer, we observed a significantly decreased glucose metabolism and amino acid uptake in both bortezomib-treated ATC cell lines. However, in vivo only SW1736 tumors responded with a decrease of the ${ }^{18} \mathrm{~F}-\mathrm{FDG}$ uptake on day 2 after treatment. Given that we did not observe any differences in growth and size of the ATC tumors or in the plasma glucose levels of the mice, we assume that the tumor perfusionand, therefore, the drug availability-differed in SW1736 and C643 tumors. Besides differences in perfusion, additional factors might have contributed to the different effect of bortezomib on the ${ }^{18} \mathrm{~F}-\mathrm{FDG}$ uptake in SW1736 and C643 tumors. Generally, we observed a more pronounced response of SW1736 cells to proteasome inhibition in vitro with respect to gene expression (including that of $\mathrm{p} 21^{\mathrm{CIP} / \mathrm{WAF} 1}$ ), differentiation, and induction of apoptosis. Moreover, differences in the tumor environment recruitment of benign cells such as fibroblasts, immune cells, and endothelial cells and the secretion of protecting factors may additionally affect tumor response to therapeutic agents.

NF-кB has been shown to play an important role in the anticancer activity of proteasome inhibitors. On the basis of the stabilization of I $\kappa \mathrm{B}$, the inhibitor of the NF- $\kappa \mathrm{B}$, proteasome inhibition prevents nuclear translocation and transcriptional activity of NF- $\mathrm{KB}$ in different tumor cells including medullary thyroid carcinoma cells $(5,11)$. Our results instead demonstrated an increased NF-кB activity in SW1736 and C643 cells. This discrepancy might be explained by different experimental approaches used for the investigation of NF- $\mathrm{KB}$ activity. Furthermore, tumor cells often differ in sensitivity and response to therapeutic agents even when they originate from the same tumor entity $(24,25)$. Thus, although bortezomib mediates similar effects on apoptosis and cell cycle in carcinoma cell lines, the NF- $\kappa$ B signaling pathway might be differently affected in ATC cells. More importantly, we
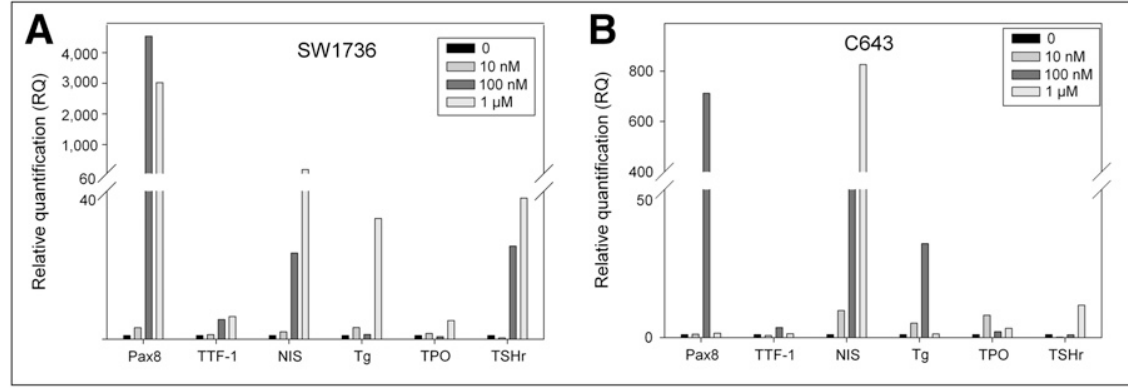

FIGURE 6. Quantification of thyroid-specific gene expression in SW1736 (A) and C643 (B) cells after bortezomib treatment for $24 \mathrm{~h}$. Values represent relative quantification of bortezomib-treated vs. untreated cells evaluated by qPCR using Pax8-, TTF1-, NIS-, thyroglobulin-, thyroperoxidase-, and $\mathrm{TSH}$-specific probes. GAPDH was used as endogenous control. 
FIGURE 7. Uptake of ${ }^{125}$ iodide within $1 \mathrm{~h}$ in SW1736 (A) and C643 (B) cells untreated or treated with indicated bortezomib concentrations for $72 \mathrm{~h}$ (uptake experiment). In efflux experiment, intracellular radioactivity of tumor cells was evaluated at 20 min after $\mathrm{Na}^{125}$-containing medium had been replaced by nonradioactive medium. Counts (cpm) for each sample were normalized to $10^{5}$ cells. Data represent mean values and SD of triplicate samples from representative experiment. ${ }^{*} P \leq 0.05$. ${ }^{\star \star} P \leq 0.01$
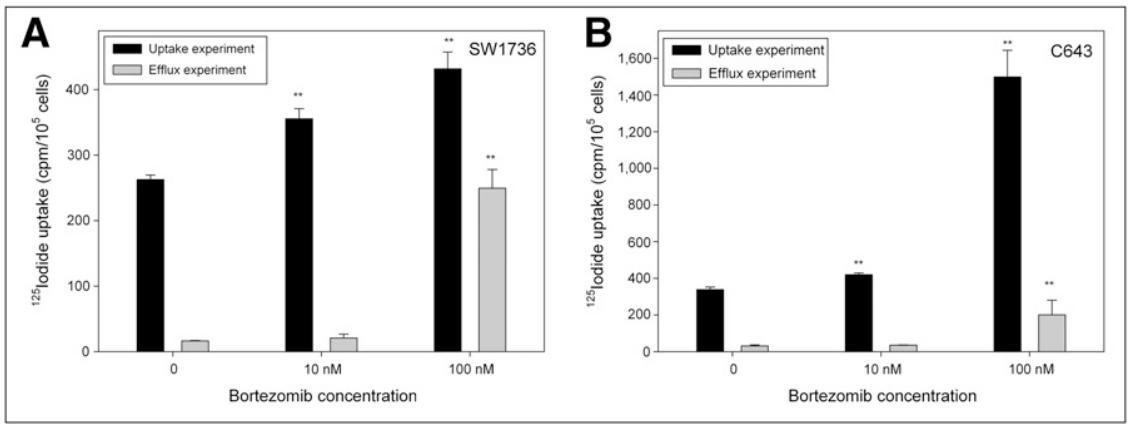

and others $(8,26)$ suggest that $\mathrm{NF}-\kappa \mathrm{B}$ inhibition may not be the sole mediator of the anticancer activity of bortezomib. Our gene chip analysis demonstrated a specific coordinated pattern of transcriptional changes in bortezomib-treated ATC cells similar to that already observed for multiple myeloma cells (8). Besides the upregulation of genes involved in apoptosis, cell cycle, and growth signaling, we noticed a significant increase of hsp transcripts in both ATC cell lines. Especially, inductions of the hsp-70, hsp-90, hsp40, and hsp-27 families were the most pronounced responses to bortezomib, likely reflecting a stress response to the therapeutic agent, and are consistent with the welldocumented role of these molecular chaperones in conferring protection against therapeutic agents (27). Furthermore, bortezomib triggered transcription of components of the proteasome-ubiquitin pathway, including the proteasome 26s subunits in C643 cells and enzymes involved in ubiquitination in both ATC cells. Obviously, tumor cells attempt to compensate for the loss of proteasome activity by synthesizing new proteasomes. Although these cytoprotective responses are insufficient to rescue ATC cells from apoptosis, they indicate that proteasome activity is required for cell survival. In SW1736 cells, bortezomib also induced the upregulation of FAF1, which is involved in protein degradation (28), negative regulation of NF- $\mathrm{BB}$ activity (29), chaperone activity of hsps (30), and induction of apoptosis (31). Therefore, FAF1 might be considered an important factor in therapeutic response to the treatment with bortezomib.

Finally, we demonstrated that bortezomib upregulates transcription of Pax8, TTF-1, and thyroid-specific target genes in the ATC cells. In addition, we measured an increased uptake of radioiodide in both cell lines, which, however, washed out of C643 cells within 20 min to more than $90 \%$ but less than $43 \%$ of SW1736 cells. These data implicate that bortezomib initiates a redifferentiation process in both cell lines, restoring to a low to moderate extent the functional activity of NIS. The intracellular accumulation of iodide additionally depends on the coupling to tyrosine residues of thyroglobulin by thyroperoxidase. The fact that SW1736 cells concentrated iodide to a moderate extent whereas C643 cells failed to do so implies that the ATC cells differed with respect to expression and functional activity of thyroperoxidase and thyroglobulin.

\section{CONCLUSION}

The present study showed that bortezomib provides strong antitumor effects, including cycle arrest, apoptosis, and changes in metabolism in ATC. In patients, the maximal concentration for bortezomib is around $112 \mathrm{ng} /$ $\mathrm{mL}$, with a half-life of 9-15 h. In our cell experiments, we used concentrations between 4 and $400 \mathrm{ng} / \mathrm{mL}$. Therefore, our experimental procedures underlying the in vitro and in vivo data correspond to the clinical situation. We also observed that the upregulation of thyroid-specific gene expression restores to some extent the capacity of iodide accumulation in ATC cells. However, the effectiveness of radioiodide therapy critically depends on the local concentration and the biologic half-life of the isotope in the tumor. To achieve therapeutically useful absorbed doses in vivo, a longer exposure with low doses of bortezomib may result in a more pronounced redifferentiation and higher iodide uptake as has been observed in patients with non-iodideconcentrating differentiated thyroid carcinoma after longterm treatment with retinoic acid (32). Thus, combining bortezomib with agents that additionally affect metabolism, sensitivity, and redifferentiation of ATC cells could improve the clinical outcome. For instance, in thyroid carcinoma cells, the histone deacetylase inhibitor MS-275 was shown to enhance the functional activity of NIS (25), and the combination of histone acetylase inhibitors and proteasome inhibitors synergistically enhanced TRAIL-mediated apoptosis (33). Thus, bortezomib may be considered a promising therapeutic agent for the treatment of anaplastic thyroid carcinoma in the setting of a combination therapy, but further investigation is clearly warranted to improve clinical outcome.

\section{DISCLOSURE STATEMENT}

The costs of publication of this article were defrayed in part by the payment of page charges. Therefore, and solely to indicate this fact, this article is hereby marked "advertisement" in accordance with 18 USC section 1734.

\section{ACKNOWLEDGMENTS}

We thank Gabriela Glensch, Iris Wolf, and Ulrike Bauder-Wüst for their excellent technical assistance concerning the cell culture experiments and Karin Leotta for 
the performance of the animal experiments. Bortezomib was kindly provided by Harald Goldschmidt, University Hospital Heidelberg. No other potential conflict of interest relevant to this article was reported.

\section{REFERENCES}

1. Elisei R, Vivaldi A, Agate L, et al. All-trans-retinoic acid treatment inhibits the growth of retinoic acid receptor beta messenger ribonucleic acid expressing thyroid cancer cell lines but does not reinduce the expression of thyroid-specific genes. J Clin Endocrinol Metab. 2005;90:2403-2411.

2. Ros P, Rossi DL, Acebron A, et al. Thyroid-specific gene expression in the multistep process of thyroid carcinogenesis. Biochimie. 1999;81:389-396.

3. Haugen BR, Larson LL, Pugazhenthi U, et al. Retinoic acid and retinoid X receptors are differentially expressed in thyroid cancer and thyroid carcinoma cell lines and predict response to treatment with retinoids. J Clin Endocrinol Metab. 2004;89:272-280.

4. Voorhees PM, Dees EC, O'Neil B, et al. The proteasome as a target for cancer therapy. Clin Cancer Res. 2003;9:6316-6325.

5. Adams J. The development of proteasome inhibitors as anticancer drugs. Cancer Cell. 2004;5:417-421.

6. Hideshima T, Richardson P, Chauhan D, et al. The proteasome inhibitor PS-341 inhibits growth, induces apoptosis, and overcomes drug resistance in human multiple myeloma cells. Cancer Res. 2001;61:3071-3076.

7. Papandreou CN, Daliani DD, Nix D, et al. Phase I trial of the proteasome inhibitor bortezomib in patients with advanced solid tumors with observations in androgen-independent prostate cancer. J Clin Oncol. 2004;22:2108-2121.

8. Mitsiades N, Mitsiades CS, Poulaki V, et al. Molecular sequelae of proteasome inhibition in human multiple myeloma cells. Proc Natl Acad Sci USA. 2002;99: 14374-14379.

9. Livak KJ, Schmittgen TD. Analysis of relative gene expression data using real time quantitative PCR and the $2^{-\Delta \Delta \mathrm{CT}}$ method. Methods. 2001;25:402-408.

10. Haberkorn U, Henze M, Altmann A, et al. Transfer of the human NaI symporter gene enhances iodide uptake in hepatoma cells. J Nucl Med. 2001;42:317325.

11. Mitsiades CS, McMillin D, Kotoula V, et al. Antitumor effects of the proteasome inhibitor bortezomib in medullary and anaplastic thyroid carcinoma cells in vitro. J Clin Endocrinol Metab. 2006;91:4013-4021.

12. Pacifico F, Mauro C, Barone C, et al. Oncogenic and anti-apoptotic activity of NF-кB in human thyroid carcinomas. J Biol Chem. 2004;279:54610-54619.

13. Wendt J, Radetzki S, von Haefen C, et al. Induction of p21CIP/WAF-1 and G2 arrest by ionizing irradiation impedes caspase-3-mediated apoptosis in human carcinoma cells. Oncogene. 2006;25:972-980.

14. Hollander MC, Zhan Q, Bae I, Fornace AF Jr. Mammalian GADD34, an apoptosis- and DNA and damage-inducible gene. J Biol Chem. 1997;272:1373113737.

15. Fabbro D, Di Loreto C, Beltrami CA, et al. Expression of thyroid transcription factors TTF-1 and Pax-8 in human thyroid neoplasms. Cancer Res. 1994;54: 4744-4749.
16. Di Palma T, Nitsch R, Mascia A, et al. The paired-domain containing factor Pax 8 and the homeodomain-containing factor TTF-1 directly interact and synergistically activate transcription. J Biol Chem. 2003;278:3395-3402.

17. Miccadei S, De Leo R, Zammarchi E, et al. The synergistic activity of thyroid transcription factor 1 and Pax 8 relies on the promoter/enhancer interplay. Mol Endocrinol. 2002;16:837-846.

18. Riedel C, Levy O, Carrasco N. Post-transcriptional regulation of the sodium/ iodide symporter by thyrotropin. J Biol Chem. 2001;276:21458-21463.

19. Ando T, Kawabe $\mathrm{T}$, Ohara $\mathrm{H}$, et al. Involvement of the interaction between $\mathrm{p} 21$ and proliferating cell nuclear antigen for the maintenance of G2-M arrest after DNA damage. J Biol Chem. 2001;276:42971-42977.

20. Wuerzberger-Davis SM, Chang P-Y, Berchtold C, et al. Enhanced $\mathrm{G}_{2}-\mathrm{M}$ arrest by nuclear factor-kB-dependent $\mathrm{p} 21^{\text {waf } 1 / \mathrm{cip} 1}$ induction. Mol Cancer Res. 2005;3: 345-353.

21. Mitsiades N, Poulaki V, Tseleni-Balafouta S, et al. Thyroid carcinoma cells are resistant to FAS-mediated apoptosis but sensitive to tumor necrosis factor-related apoptosis-inducing ligand. Cancer Res. 2000;60:4122-4129.

22. Brooks $\mathrm{AD}$, Jacobsen $\mathrm{KM}, \mathrm{Li} \mathrm{W}$, et al. Bortezomib sensitizes human renal carcinomas to TRAIL apoptosis through increased activation of caspase- 8 in the death-inducing signaling complex. Mol Cancer Res. 2010;8:729-738.

23. Haberkorn U, Markert A, Mier W, Askoxylakis V, Altmann A. Molecular imaging of tumor metabolism and apoptosis. Oncogene. 2011;30:4141-4151.

24. Strauss SJ, Higginbottom K, Jüliger S, et al. The proteasome inhibitor bortezomib acts independently of p53 and induces cell death via apoptosis and mitotic catastrophe in B-cell lymphoma cell lines. Cancer Res. 2007;67:27832790 .

25. Altmann A, Eisenhut M, Bauder-Wüst U, et al. Therapy of thyroid carcinoma with the histone deacetylase inhibitor MS-275. Eur J Nucl Med Mol Imaging. 2010;37:2286-2297.

26. Hideshima T, Chauhan D, Richardson $\mathrm{P}$, et al. NF-кB as a therapeutic target in multiple myeloma. J Biol Chem. 2002;277:16639-16647.

27. Lee DH, Goldberg AL. Proteasome inhibitors cause induction of heat shock proteins and trehalose, which together confer thermotolerance in Saccharomyces cerevisiae. Mol Cell Biol. 1998;18:30-38.

28. Song EJ, Yim S-H, Kim N-S, et al. Human Fas-associated factor 1, interacting with ubiquitinated proteins and valosin-containing protein, is involved in the ubiquitin-proteasome pathway. Mol Cell Biol. 2005;25:2511-2524.

29. Park M-Y, Jang HD, Lee SY, et al. Fas-associated factor-1 inhibits nuclear factor$\kappa \mathrm{B}(\mathrm{NF}-\kappa \mathrm{B})$ activity by interfering with nuclear translocation of RelA (p65) subunit of NF-кB. J Biol Chem. 2004;279:2544-2549.

30. Kim H-J, Song EJ, Lee Y-S, et al. Human Fas-associated factor 1 interacts with heat shock protein 70 and negatively regulates chaperone activity. J Biol Chem. 2005;280:8125-8133.

31. Ryu SW, Lee SJ, Park MY, et al. Fas-associated factor 1, FAF1, is a member of Fas-death-inducing signaling complex. J Biol Chem. 2003;278:24003-24010.

32. Grünwald F, Pakos E, Bender H, et al. Redifferentiation therapy with retinoic acid in follicular thyroid cancer. J Nucl Med. 1998;39:1555-1558.

33. Borbone E, Berlingieri MT, De Bellis F, et al. Histone deacetylase inhibitors induce thyroid cancer-specific apoptosis through proteasome-dependent inhibition of TRAIL degradation. Oncogene. 2010;29:105-116. 